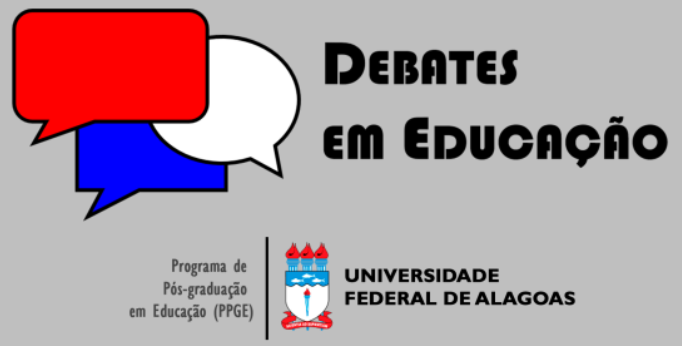

ISSN Eletrônico 2175-6600

Vol. I I | No. 23 | Jan./Abr. | 2019

Susana Margulies

Universidad de Buenos Aires (UBA - Argentina) sumargulies@gmail.com

María Julia Name

Universidad de Buenos Aires (UBA - Argentina) namejulia@gmail.com

\section{EL “ESTUDIO ANTROPOLÓGICO” DE UNA NIÑA ACHÉ A COMIENZOS DEL SIGLO XX: EL ABORDAJE DEL RACISMO EN UN CURSO DE HISTORIA DE LA DISCIPLINA}

\section{RESUMO}

Este artículo presenta la experiencia de docencia e investigación desarrollada en torno del tratamiento de la problemática del racismo en un curso universitario de grado sobre historia de la antropología a partir de la incorporación al programa de un estudio del naturalista Lehmann-Nitsche sobre los caracteres físicos y comportamientos de una niña indígena aché que se constituyó en objeto de observación e investigación de la ciencia antropológica de fines del siglo XIX y comienzos del XX. En este proceso fue de fundamental importancia la participación del equipo de cátedra en la investigación para la realización del film documental Damiana Kryygi, de A. Fernández Mouján, estrenado en 2015 y que desde entonces se proyecta y debate como parte del dictado de la materia.

Palavras-chave: Historia de la antropología. Racismo. Fotografía.

\section{THE “ANTHROPOLOGICAL STUDY” OF AN ACHÉ GIRL AT THE BEGINNING OF THE 20TH CENTURY: THE APPROACH OF RACISM IN A COURSE OF HISTORY OF ANTHROPOLOGY}

\begin{abstract}
This article presents the experience of teaching and research developed around the treatment of the problem of racism in a university undergraduate course of history of anthropology from the incorporation into the program of study by the naturalist Lehmann-Nitsche on physical characteristics and behavior of an Aché indigenous girl who became a scientific object of observation and research of anthropological science of the late nineteenth and early twentieth centuries. In this process, was a fundamental importance the participation of the teaching staff in the research to produce the documentary film Damiana Kryygi, by A. Fernández Mouján, premiered in 2015 and that since then is projected and discussed as part of the course activities.
\end{abstract}

Keywords: History of anthropology. Racism. Photography.

Submetido em: 29/01/2019

Aceito em: 07/02/2019

Ahead of print em: 07/03/2019

Publicado em: 25/04/2019

do http://dx.doi.org//0.28998/2175-6600.2019v I In23p390-404 


\section{INTRODUCCIÓN}

La enseñanza de la historia de la disciplina en la formación de grado en ciencias antropológicas presenta desafíos específicos para quienes asumen esta tarea desde la docencia. Lejos de una simple transmisión de teorías y propuestas conceptuales y de la reconstrucción de escenarios geográficos e institucionales del pasado, los alcances de este "oficio" son mayores en tanto obligan a una reflexión constante sobre los significados y los objetivos de la enseñanza de la historia de la disciplina. En el ejercicio de dar carnadura concreta a procesos del pasado nos encontramos en reiteradas ocasiones investigando y "dialogando" con los/as autores/as y reformulando constantemente aquella historia que transmitimos. En ese sentido sostenemos, siguiendo a M. Peirano (2006), que, al igual que la teoría, la historia de la disciplina es un fenómeno "vivo": enseñarla supone, al mismo tiempo, construirla y reformularla a la luz de nuevos interrogantes o a partir de la aparición de nuevos datos.

Con vistas a contribuir a la propuesta de este dossier sobre la enseñanza de la disciplina, en este artículo presentamos la experiencia en docencia e investigación desarrollada en el marco de un curso universitario de grado sobre la historia de la teoría antropológica. Dicho proceso contribuyó a la formulación de algunas reflexiones sobre la propia práctica de enseñar historia de la disciplina, entendiendo que ésta forma parte de su "metateoría" (KROTZ, 1987) y que constituye en sí misma una práctica antropológica.

\section{I.I El ámbito institucional}

El proceso que se presenta a continuación se desarrolla en el marco de la asignatura Historia de la Teoría Antropológica, que forma parte de la carrera de grado en Ciencias Antropológicas que se dicta en la Facultad de Filosofía y Letras de la Universidad de Buenos Aires (FFyL-UBA). La materia tiene como propósito presentar un cuadro de referencia histórico y teórico para la comprensión de la trayectoria social e intelectual de la antropología, tomando como punto de partida el siglo XVIII y los fundamentos de la Modernidad y extendiéndose hasta el fin del período de entreguerras europeo-norteamericano. programa propone analizar estos desarrollos en los escenarios geográfico-académicos que fueron más significativos en el desarrollo de la "antropología clásica" (a saber: Francia, Inglaterra, Estados Unidos y Alemania), y toma como referencia un conjunto de autores clave del período abordado. Propone un enfoque analítico que articula lo que M. Peirano (2006) denomina la mirada "historiográfica" con una perspectiva de "historia teórica". Esto es, un enfoque que sitúa a los autores y a las obras en su contexto (histórico, político, institucional, etc.) intentando entenderlos desde ese posicionamiento y que, a la vez, 
hace el ejercicio de "dialogar" teórica y conceptualmente con las fuentes originales permitiendo así la reformulación constante de las lecturas que efectuamos sobre el pasado. Ese ejercicio -entendemosfavorece la construcción de nuestros propios "linajes intelectuales" a partir de las preocupaciones y problemas actuales de la disciplina.

La carrera de Ciencias Antropológicas de la FFyL-UBA es, junto con la de la Facultad de Ciencias Naturales y Museo de la Universidad Nacional de la Plata (FCNyM-UNLP), una de las más antiguas en la Argentina.' Desde su creación, en 1958, hasta el presente se han sucedido en total seis planes de estudio cuya vigencia, estructuración y contenidos son variables. En lo que refiere a los contenidos relativos a la historia de la disciplina, cabe mencionar que éstos han tenido mayor o menor protagonismo, según el caso. $^{2}$

Actualmente, su plan de estudios cuenta con dos orientaciones: antropología sociocultural y arqueología. El curso de Historia de la Teoría Antropológica tiene un lugar central en la formación de la/os estudiantes, tanto por su ubicación en el ciclo de materias troncales como por el tipo de contenidos. Se trata de una instancia en la que se incorporan conceptos antropológicos centrales y se entra en contacto con los principales núcleos problemáticos de la disciplina, los que continúan profundizándose a lo largo de la carrera. Se abordan entre otros los debates sobre la definición de la naturaleza humana; la racionalidad/irracionalidad de las prácticas y creencias sociales; la cuestión universalismo/particularismo y la relación entre raza y colonialismo.

\section{I.2 El abordaje del racismo en la materia Historia de la Teoría Antropológica}

El tratamiento histórico y conceptual de la cuestión del racismo es uno de los temas del programa de la materia. La propuesta consiste en problematizar la inclusión del concepto de "raza" en el campo semántico de las ciencias naturales y en particular de la antropología en el siglo XIX y analizar cómo, en tanto instrumento de expansión imperial, el mismo proporcionó el lenguaje científico (y por ende, el

\footnotetext{
I Ambas fueron creadas a fines de la década de 1950 en el contexto de lo que algunos autores denominan el "proceso de modernización" de las universidades argentinas. Actualmente hay trece instituciones pertenecientes al ámbito público que ofrecen formación de grado en ciencias antropológicas (en arqueología y/o en antropología sociocultural): Universidad Nacional de La Plata, Universidad de Buenos Aires, Universidad Nacional de Rosario, Universidad Nacional de Misiones, Universidad Nacional del Centro de la Provincia de Buenos Aires, Universidad Nacional de Salta, Universidad Nacional de Jujuy, Universidad Nacional de Catamarca, Universidad Nacional de Río Negro, Universidad Nacional de Gral. San Martín, Universidad Nacional de Córdoba, Universidad Nacional de Tucumán, Universidad Nacional de Cuyo.

${ }^{2}$ Los planes de estudio corresponden a los siguientes años: 1958 (Res. CS 50/58), 1972 (Res. CS 1277/72), 1974 (Res. CS 375/74), 1975 (Res. CS 91/74), 1976 (Res. CS 153/76) y 1985 (Res. CS 79/85). Mientras que en algunos casos la historia de la disciplina se encuentra ausente (por ejemplo, en el plan 1958 y en el plan 1976), en otros ocupa un lugar preponderante, como en el plan 1974 que incluye los cursos obligatorios "Teoría e Historia de la Antropología I", "Teoría e Historia de la Antropología II" y "Seminario de Historia de la Antropología Argentina". Para más detalle sobre los planes y sus contenidos, véase Perazzi y Name (20 I8).
} 
lenguaje "autorizado") a través del cual se pasó a describir, clasificar y subordinar a las poblaciones "nativas" de los territorios conquistados como tipos raciales que los europeos consideraron moralmente inferiores (POOLE, 2002). La construcción de esos tipos raciales, elaborados sobre la base de caracteres pretendidamente objetivos (medidas, formas, tamaños, etc.) fue uno de los pilares de la antropología de fines del siglo XIX, siendo clave el registro visual y la apelación a la fotografía por su posibilidad de representar anatomías y fisonomías y delimitar tales tipos (MARTíNEZ, 20 I2).

Desde el año 200 I se incorporó al programa de la materia el artículo "Relevamiento antropológico de una india guayakí" escrito por Robert Lehmann-Nitsche, un naturalista y médico de origen alemán que migró a la Argentina a fines del siglo XIX y estuvo a cargo de la dirección de la Sección de Antropología del Museo de Ciencias Naturales de La Plata entre 1897 y 1930. ${ }^{3}$ Este escrito, publicado en el año 1908 en la Revista del Museo de La Plata, una prestigiosa revista de antropología de Argentina, se presenta como una contribución al campo de investigaciones de la antropología física. Este tipo de investigaciones, realizadas entre fines del siglo $X I X$ y comienzos del $X X$, presentaba un fuerte interés por el estudio de las "variedades corporales" de las poblaciones nativas, impulsando la realización de numerosos trabajos orientados a la conformación de un repositorio de datos para el estudio de la morfología humana (PERAZZI, 2009). Llenar los vacíos del mapa etnográfico sudamericano y registrar y coleccionar objetos pertenecientes a aquellos pueblos indígenas que se veían como "razas en desaparición" era para el autor del artículo "la tarea que moral y científicamente la antropología sudamericana" debía "seguir" (LEHMANNNITSCHE, I899, p. 123- 124). Se especializó para ello en el estudio de los "caracteres físicos descriptivos" para la clasificación de las razas humanas a partir de rasgos fisonómicos y corporales. Clasificación tanto física como moral, dada "la creencia según la cual los 'signos exteriores' expresaban el estado psíquico del individuo" (PERAZZI, 2009, p. 125). Convicción que no admitía "controversias ni dobles lecturas: era un hecho científicamente aceptado" (Idem, p. 125).

Lehmann-Nitsche viajó ampliamente y realizó estudios antropológicos de diversos tipos raciales de pueblos de la Argentina. Su último trabajo en este tópico fue el citado "Relevamiento antropológico de una india Guayaquí". A lo largo de sus páginas, el autor realiza una serie de observaciones "antropológicas" sobre una niña aché capturada en Paraguay y bautizada con el nombre de Damiana, presentada como un ejemplar de una etnia que resultaba de interés particular para los estudiosos de las razas humanas. Describe

\footnotetext{
${ }^{3}$ La antropología alemana tuvo importantes representantes en nuestro país que se instalaron en instituciones académicas de prestigio. En el Museo de La Plata, el Dr. Paul Adolf Robert Lehmann-Nitsche (I 872-1938) dirigió la Sección Antropología desde 1897 hasta su retiro en 1930, cuando regresó a Alemania (ARENAS, 1991; PERAZZI, 2009; MARTÍNEZ, 20I2). Habiendo obtenido los títulos de Doctor en Ciencias Naturales (año 1893) y Doctor en Medicina (año I 897), se trasladó a la Argentina a los 25 años de edad para ocupar el cargo de conservador de la Sección Antropológica del Museo de Ciencias Naturales de La Plata, sucediendo a Herman ten Kate en dicha función (FARRO, 2009a). En 1905 fue designado profesor de antropología en la Universidad de Buenos Aires. Según señalan Koel-Abt y Winkelmann, "durante sus últimos años, dio conferencias sobre la historia sudamericana en la Universidad de Berlín. Nada indica que en ese tiempo se haya vinculado con la nueva especialidad de la higiene racial" (2013, p. 396, traducción propia).
} 
la estructura corporal de la niña, incluidos los caracteres de aquello que denomina "miembros posteriores" (con esta expresión se refiere a sus piernas), la forma de la cabeza y el color y la forma del cabello, la piel y los ojos. Toma medidas de su cuerpo y las vuelca en cuadros comparativos. Las medidas no muestran, a su entender, anomalía alguna: la talla, las extremidades y el cráneo son, en su opinión, "normales" y semejantes a los de las "niñas germánicas de la misma edad" (LEHMANN-NITSCHE, I899, p. 98), quienes proveen así el canon de proporciones para el "ideal anatómico" (MARTíNEZ, 20 I2). A la descripción y el análisis antropométrico agrega apreciaciones con una clara impronta moralizadora referida a la conducta sexual de la joven manifiesta en la forma de sus mamas. Describe asimismo la actitud "reservada, esquiva y desconfiada" de la joven, y "la curiosa expresión de su mirada" (LEHMANN-NITSCHE, I899, p. 93) evidenciada en una fotografía que ilustra el escrito, proveniente de unas sesiones fotográficas realizadas en 1907 en el Hospital de Melchor Romero cercano a la ciudad de La Plata. Fotografía que muestra a Damiana, de cuerpo entero, desnuda contra una pared, el brazo derecho hacia atrás y la mirada esquivando en efecto el foco de la lente.

El estudio ofrece alguna información sobre la historia de la niña y sobre cómo llegó a estar a disposición de Lehmann-Nitsche para que éste la tomara como su objeto de estudio: su captura siendo muy pequeña, el primer estudio a cargo de una expedición científica del Museo de la Plata en Paraguay, su traslado a La Plata, su entrega para servir como criada en el hogar de una importante figura intelectual de esa ciudad, su separación de esa casa y la mudanza al Instituto Neuropsiquiátrico de Melchor Romero, su muerte por tuberculosis, la disección de sus restos con la incorporación de su esqueleto al acervo del Museo de la Plata y el envío a Berlín de su cabeza.

La incorporación de este texto al programa de la materia permitió, en una primera etapa, generar entre la/os estudiantes un vívido acercamiento a la materialidad de la clasificación y categorización de las razas humanas a fines del siglo XIX. A través de la reconstrucción "antropométrica" y "antroposcópica" propuesta por el autor y del análisis de las medidas anatómicas y la representación fotográfica del cuerpo desnudo, Damiana cobra el estatus de espécimen antropológico.

\section{EL “ENCUENTRO” CON LA HISTORIA DE DAMIANA}

\section{I Hallazgo y restitución de los restos}

En el año 2007, el esqueleto sin el cráneo de Damiana fue hallado por Fernando Pepe, coordinador del colectivo GUÍAS (Grupo Universitario de Investigación en Antropología Social) de la FCNyM-UNLP, en una caja bajo una de las vitrinas de la sala de Antropología Biológica. Por intermedio de Patricia Arenas, 
docente e investigadora de la Universidad Nacional de Tucumán (UNT), el colectivo GUÍAS tomó contacto con la Federación Nativa Aché del Paraguay (FENAP) y con la organización LINAJE (Liga Nativa por la Autonomía, Justicia y Ética) e impulsó un proceso de reclamo que culminó en junio de 20 I 0 con la restitución de los restos por parte de la dirección del Museo de La Plata. Los ancianos de las comunidades dieron a Damiana un nombre aché, Kryygi, y así fue enterrada en el Parque Nacional Caazapá, una reserva natural que reclaman al estado paraguayo como parte de su territorio ancestral. Tras una larga historia de matanzas, robo y asesinato de niños y mujeres, enfermedades, salida y sedentarización forzosa en la "Colonia Nacional Aché-Guayakí" de Cerro Morotí entre 1970 y 1978 durante la dictadura de Stroessner, en un proceso caracterizado por ellos mismos y por estudiosos como M. Münzel (2008a y 2008b) como genocidio, a partir de los 2000 los aché retornaron a sus tierras ancestrales, se organizaron en siete comunidades en la región oriental de Paraguay y constituyeron una federación. ${ }^{4}$

El cráneo fue ubicado en 201 I en Berlín, donde formaba parte de la colección de restos óseos del Hospital Universitario Charité. Había sido ingresado en 1911 en la colección del antiguo Instituto de Anatomía de Berlín. El mismo, junto con el cuero cabelludo de Damiana, parte de su cabellera y una porción de la lengua que estaba conservada en formol fueron restituidos en abril de 20।2. El reclamo lo efectuaron las dos organizaciones del pueblo aché del Paraguay, la FENAP y LINAJE. El trabajo institucional de restitución fue organizado por el Institute of Vegetative Anatomy a cargo de Andreas Winkelmann y otros integrantes, quienes desde 2010 llevaban adelante el "Charité Human Remains Project" con el objetivo de investigar las colecciones antropológicas del Hospital (provenientes básicamente de África y Oceanía) y explorar su relación con la historia colonial y de la ciencia alemanas. ${ }^{5}$

En abril de 2012, estos restos fueron recibidos en la embajada de Paraguay en Berlín y, una vez en Asunción, fueron entregados a los representantes de las organizaciones aché quienes, en una ceremonia realizada en el Museo de las Memorias de esa ciudad, expresaron su demanda de pedido de perdón por parte del gobierno paraguayo y "una reparación histórica (...) por el despojo de los territorios ancestrales (...), por la desaparición de tantas víctimas asesinadas o raptadas y convertidas, al igual que la niña Kryygi, en trofeos de cacería o de ciencia" (extractado del "Comunicado de los Aché de la FENAP y LINAJE", 20 I2). ${ }^{6}$ El día 5 de mayo fueron enterrados junto con los restos restituidos en 2010 , "para unir el cráneo y el cuerpo de Kryygimaî y rendir a nuestra hermana los últimos homenajes y saludos rituales" (Idem)

\footnotetext{
${ }^{4}$ Las organizaciones aché llevan actualmente adelante una demanda por genocidio ante tribunales de Paraguay y Argentina. Véase http://www.linaje.org/

${ }^{5}$ Véase : https://anatomie.charite.de/ueber_den_faecherverbund/human_remains_projekt/

${ }^{6}$ Comunicado completo disponible en: $\underline{h t t p: / / w w w . l i n a j e . o r g / v l / l e e r ~ n o t i c i a s . p h p ? i d=44}$
} 
A partir de $201 \mathrm{I}$, confluyendo con la investigación para el proyecto de un film documental de Alejandro Fernández Mouján, ${ }^{7}$ una parte del equipo de la cátedra se planteó profundizar en el conocimiento de la historia de Damiana Kryygi. Desde entonces trabajo de cátedra y proyecto cinematográfico coincidieron en una búsqueda común que denominamos "tras las huellas de Damiana" orientada a reconstruir los eventos, los documentos, las instituciones, las escenas y los paisajes hoy transformados en Argentina, Paraguay y Alemania en los que se sucedió esta historia. Ello implicó, en un comienzo, seguir las "pistas" que aparecían en el artículo de Lehmann-Nitsche para luego ir completando y llenando los vacíos de esa historia a través de la búsqueda en publicaciones, las cartografías de la época y en distintas fuentes y archivos. Se contó asimismo con el significativo aporte de especialistas que orientaron la indagación y aportaron nuevos datos. Los resultados de este proceso posibilitaron la obtención de material e información que sirvieron para situar las escenas y relaciones que aparecen referenciadas en el escrito de Lehmann Nitsche, incluyendo la ubicación del lugar probable tanto de la captura de la niña en Encarnación como de la sesión fotográfica en que se tomó la imagen que acompaña el texto. Estos avances aportaron al encuentro y al reconocimiento de Damiana desde una nueva perspectiva o ángulo de visión: ya no sólo en términos de su transformación en espécimen u objeto de estudio científico sino también como persona "extraída" de su "cosmos" (PRATT, 1997), negada su historia y separada de su condición de sujeto.

La película Damiana Kryygi fue estrenada en $2015^{8}$ y desde entonces se utiliza como material de trabajo en la asignatura.

\subsection{La reconstrucción de la historia: "tras las huellas" de Damiana}

En el año 1896, en la selva paraguaya, cerca de la actual ciudad de Encarnación y sobre el río Paraná, unos colonos masacran un grupo aché en represalia por la captura de un caballo y sólo sobrevive una niña de unos tres años. Los aché de entonces, nombrados por los blancos como "guayaquíes"9 eran cazadores-recolectores nómades de la selva subtropical y estaban siendo desplazados por el avance de la frontera de los blancos y despojados de los recursos para subsistir. La niña es bautizada Damiana por sus captores, y sometida a la institución del “criadazgo". Tres meses después de su captura, en enero de I897,

\footnotetext{
${ }^{7}$ La misma contó para su realización a partir de 2010 con un crédito del Instituto Nacional de Artes Audiovisuales de la Argentina. ${ }^{8}$ El estreno fue el 2 I de mayo de 2015 en la ciudad de Buenos Aires, y en setiembre de ese año en la comunidad Chupa Pou del Paraguay. El film ha recibido desde entonces varias distinciones entre las que se puede mencionar el premio al mejor largometraje documental en 2015 en el "Film \& Media Festival" de la Society for Visual Anthropology en la II 4 Reunión de la American Anthropological Association en Denver, EUA.

9 El término "guayakí" es considerado despectivo por los aché.
} 
los integrantes de una expedición el Museo de La Plata, Herman ten Kate y Charles de La Hitte, ${ }^{10}$ fotografían a la pequeña, quien es llevada ante ellos en Encarnación por el entonces comandante de la guarnición militar.

La "cuestión guayakí" despertaba un fuerte interés incluso público y en su estudio participaron colonos, misioneros y etnólogos alemanes de enfoque difusionista como Federico Vogt de la orden católica Societas Verbi Divini I' (Martínez, 2012). En 1897, ten Kate y La Hitte publican en francés en los Anales del Museo de La Plata "Notes ethnographiques sur les Indiens Guayakí". Allí se equipara a los aché con pueblos de Asia y África, y se los caracteriza como "ejemplos (...) de supervivencia de razas primitivas (...) de pequeña talla" que "viven en los bosques (...) y desaparecen delante del elemento invasor que las rodea" (TEN KATE y LA HITTE, I897, p. 38. Traducido en MARTÍNEZ, 20 I2, p. 77). Se dice, asimismo, que representan "el grupo más austral, los menos numerosos, más homogéneos y los más primitivos posiblemente de esta antigua raza de hombres dispersada en las inmensas soledades silvestres de América del Sur" (TEN KATE y LA HITTE, 1897, p. 32. Traducido en MARTÍNEZ, 20 I2, p. 79). En la segunda parte de este trabajo ten Kate presenta mediciones antropométricas hechas sobre un esqueleto y sobre niños cautivos, incluida Damiana. Así, antropólogos del Museo de Ciencias Naturales de La Plata en Argentina la toman muy tempranamente como objeto en sus estudios sobre las variedades corporales de las poblaciones nativas.

Después de este momento se pierden las huellas de Damiana durante casi dos años. Lo más probable es que haya sido trasladada desde Villa Encarnación a la ciudad de La Plata por ten Kate y De la Hitte. Alejandro Korn, médico y maestro de la filosofía argentina y figura de importante desempeño en el mundo académico, científico y político de la ciudad recientemente fundada, la habría recibido hacia fines de 1898, poniéndola a servir en su casa materna. Transcurren unos diez años en la casa de la señora Korn, con quien la niña aprende algo de alemán hasta que en abril de 1907 debe ser retirada de allí a causa de una alegada promiscuidad sexual sin control. A la edad aproximada de 14 años, Damiana se convierte en amenaza a la intimidad doméstica de la señora Korn y su hijo Mauricio (ARENAS y PINEDO, 2005). Sobre la situación, Lehmann-Nitsche escribió:

\footnotetext{
${ }^{10}$ Herman Frederik Carel ten Kate Jr. (1858-1931) fue un científico de origen holandés cuya trayectoria de formación incluyó numerosos cursos en diversas disciplinas - medicina, geografía, geología, paleontología, etnología, antropología física, lingüística, etc.- en instituciones francesas y alemanas y un doctorado en zoología en la Universidad de Heidelberg (FARRO, 2009a). Fue el "primer encargado de la Sección Antropológica del Museo de La Plata" (FARRO, 2009b. p. 9), donde se desempeñó en dos momentos: primero, durante seis meses en el año 1893, cuando por ofrecimiento de Francisco P. Moreno realizó tareas de campo y de gabinete tanto en la Sección Arqueológica como en la Antropológica. Luego, entre enero de 1896 y mayo de 1897 , cuando estuvo a cargo de la Sección Antropológica. Por su parte, Charles de La Hitte (1 856-1927) fue asistente de ten Kate. Trabajó en el Museo de la Plata, primero como ayudante de la Sección Antropológica y luego como segundo preparador, a partir del $1{ }^{\circ}$ de enero de 1896 . Fue exonerado en octubre de 1897.

" A la misma pertenecía Wilhelm Schmidt, de la Escuela de Viena, interesado en el estudio de los pigmeos que representaban según su perspectiva la condición física y cultural humana más arcaica.
} 
La libido sexual se manifestó de una manera tan alarmante que toda educación y todo amonestamiento por parte de la familia resultó ineficaz. (...) Consideraba los actos sexuales como la cosa más natural del mundo y se entregaba a satisfacer sus deseos con la espontaneidad instintiva de un ser ingenuo (LEHMANN-NITSCHE, 1908, pp. 92-93).

Se expresaba así el discurso sobre la promiscuidad esencial asociada al otro racial, presentado como incapaz de captar los límites de la libertad y sin la fuerza moral para resistir el llamado de la lujuria. Esta construcción esencializadora no sólo configura a ese "otro" como amenaza frente a la aparente fragilidad de la identidad blanca y burguesa sino que contribuye a ocultar las relaciones de poder y de placer imaginario o real entre blancos y sirvientes hacia quienes precisamente se desplaza el discurso de la inmoralidad y la promiscuidad (STOLER, 1995).

Se la deriva entonces al cuidado de las enfermeras del Hospital Neuropsiquiátrico de Melchor Romero, ubicado a unos 18 kilómetros del centro de La Plata, del cual Korn era director. En mayo de ese año el científico alemán Robert Lehmann-Nitsche lleva adelante dos sesiones de fotografía de la joven desnuda.

Al parecer, se preveía luego derivarla a la Casa Correccional de Mujeres de la ciudad de Buenos al mando desde 1890 de una congregación religiosa, la Orden del Buen Pastor. Allí se enviaban mujeres para que "corrigieran las desviaciones morales que las habían llevado a delinquir" (CAIMARI, 2007, p. 7), incluyendo mujeres indígenas pampas capturadas en las campañas de conquista del llamado desierto patagónico. Las hermanas del Buen Pastor "hacían lo posible por imbuir hábitos laborales en las penadas, pero el espectro de las tareas adjudicadas era limitado: limpieza, costura, bordado, lavado y planchado" (Idem, p. 7). Ese especie de "confinamiento civilizatorio" no pudo realizarse en el caso de Damiana porque muy poco tiempo después fallece en el Hospital Melchor Romero a causa de una tuberculosis secundaria que afectó su cerebro y meninges (KOEL-ABT y WINKELMANN, 20I3). 12

Tras su fallecimiento, los restos de Damiana se trasladan desde el Hospital Melchor Romero al Museo de La Plata. Allí Lehmann-Nitsche ordena que se seccione su cabeza y se envíe a Hans Virchow de la Sociedad Antropológica de Berlín. El intercambio de especímenes era una pauta instalada en la cooperación de la comunidad científica internacional a la que Lehmann-Nitsche adscribía: el "comercio continuo con los sabios" en el decir de su compatriota Germán Burmeister, en la Argentina (citado en PERAZZI, 2009).

Hans Virchow era profesor de anatomía en la Universidad de Berlín, especialista en estudios de materiales óseos. Pese a ser crítico de los estudios raciales y del concepto de "razas puras", no se apartó del estereotipo racial de la ciencia de su época (KOEL-ABT y WINKELMANN, 20 I3). En una carta dirigida a Lehmann-Nitsche con fecha 9 de enero de 1908, escribió: "la cabeza es un regalo valioso" (VIRCHOW,

\footnotetext{
${ }^{12}$ En su estudio de 2013, Koel-Abt y Winkelmann asumen que la niña se recuperó de una tuberculosis infantil que reapareció como tuberculosis secundaria con afección de cerebro y meninges.
} 
1908b). Había recibido: la caballera con la piel de la frente y las cejas, la bóveda craneal con el cerebro, la cara desde la raíz de la nariz hacia abajo incluida la lengua. Poco después, el 18 de enero de 1908, Virchow presentó a los miembros de la sociedad de Antropología, Etnología y Prehistoria de Berlín “... la cabeza de una india Guayakí (...) Se trata de esa tribu curiosa, cuyos miembros (...) tienen una existencia tímida y escondida y en cada intento de acercamiento desaparecen, y que todavía hoy tienen una cultura de la edad de piedra" (VIRCHOW, 1908a, s/d, traducción propia).

En esa oportunidad presentó dos fotografías del rostro mortuorio de Damiana "desde la vista frontal y en vista de perfil" (VIRCHOW, I 908a, s/d, traducción propia). Las calificó como "notables".

\subsection{Nuestro acercamiento a las imágenes}

Como huellas significativas en la historia de Damiana Kryygi en manos de la ciencia, la búsqueda realizada en la investigación para la película reunió fotografías de tres momentos. En primer lugar, la de una niña de dos o tres años aún en Villa Encarnación y en manos de sus apropiadores, retratada por científicos del Museo de La Plata. En segundo lugar, aquella foto de Damiana Kryygi desnuda con aproximadamente catorce años publicada en el texto de 1908 y tomada poco antes de morir en el hospicio. A esta imagen se agregaron más tarde nuevas fotografías correspondientes a las mismas sesiones fotográficas que estuvieron disponibles en el catálogo del Instituto Iberoamericano de Berlín en 2013 y que nos acercaron a un mayor detalle sobre el lugar de la toma y la expresión de la joven. Por último, dos imágenes de su rostro mortuorio tomadas en Berlín publicadas por Virchow en 1908.

Mucho se ha escrito sobre el valor documental de la imagen y su equiparación con textos escritos al momento de obtener información útil y "reveladora" de ciertos aspectos del pasado, pero también se ha planteado que ese documento ha de abordarse en forma crítica y no mimética o centrada sólo en lo representacional. Las imágenes son producto de determinados contextos sociales en los cuales se elaboran, y ellas pueden darnos acceso a éstos. Así, trabajamos sobre esas imágenes como documentos de unos contextos históricos de producción de imágenes y de una economía visual que representó y modeló la visión colonial sobre el otro racializado (EDWARDS, 200I).

Consideramos, por ejemplo, las tecnologías disponibles en el momento y los estándares o requisitos de objetividad establecidos para las investigaciones de gabinete de la época (BRISSET MARTíN, 1999; GIORDANO, 2004) y la fotografía antropométrica. En ella la identidad del individuo fotografiado se disuelve en la del grupo ya que éste se presenta como representante o ejemplo de un tipo étnico o racial específico, como una forma de hacer visible la raza por medio de la clasificación de imágenes y, en el caso de Damiana Kryygi, como representante de los denominados en ese entonces "guayakíes" (MARTíNEZ, 20।2). Uno de los efectos de este tipo de fotografía antropométrica es suspender lo subjetivo y social en 
quien está siendo fotografiado. Merced a esta operatoria técnico-ideológica, el individuo retratado se convierte en representante de un tipo racial dentro del régimen clasificatorio de la diversidad somática y cultural de la época. La niña se tornaba así en un espécimen de un inventario racial, y de esta manera era arrojada en un modo otro del "ser". Desaparecida en contenedores de estaño a través del océano, desaparecida entre paños en las vitrinas del museo, su vida ya no contaba como vida humana y de su muerte no quedaban huellas salvo el registro de ingreso de su cuerpo al Museo de La Plata y la elegancia del gesto del intercambio de los hombres de ciencia.

Asimismo, la probable localización de la escena de la sesión fotográfica de 1907 en las afueras del pabellón de mujeres del hospicio durante la investigación para el film arrojó significativas pistas acerca de la situación y el espacio intersubjetivo detrás de las imágenes: un antropólogo - fotógrafo con su cámara ante una niña completamente desnuda en una mañana de mayo del frío otoño de ese año. Carlos Massota ha analizado las postales fotográficas de indígenas argentinos y ha estudiado vívidamente cómo "las marcas de" esos encuentros desiguales pueden quedar inscriptas y ser leídas "no sólo en las poses de la docilidad sino también en gestos y miradas de temor, rechazo, resistencia" (MASSSOTA, 200 I, p. 566). De hecho, la apreciación del gesto de Damiana remitía a una "condensación corporificada" (VÍCTORA y RUAS-NETO, $20 \mathrm{II}$ ) de ese tiempo histórico y a la vez a la singularidad de la escena fotografiada. Mostraba su anclaje en una tecnología visual nacida en el siglo XIX pero a la vez ese brazo escondido detrás de la cintura y la mirada desviada del foco hablaban de la imposición del fotógrafo/antropólogo y del gesto de la joven frente a esa inescapable situación.

E. Edwards afirma que las fotografías poseen "una performatividad, un tono afectivo, una relación con quien las mira (...)" que hace posible tratarlas como "objetos sociales activos" (...) que, aunque son "del" pasado y captan "un fragmento de espacio y tiempo, dislocado del flujo de la vida", también son "del" presente en la medida en que en el acto de mirarlas el pasado se proyecta activamente en el presente (EDWARDS, 200I, p. 18). Las fotografías son -dice la autora- objetos esencialmente relacionales. Consideramos que fue precisamente en este horizonte de pasado-presente, que lo retratado en esas fotos nos interpelaba y exigía una interpretación (AGAMBEN, 2005). Frente al presente intemporal al que la arrojaban las imágenes antropométricas, de una vida suspendida más allá de su muerte, el encuentro con la historia de la joven implicó la reposición de un tiempo, de una vida, un nombre, una muerte (y una causa de muerte) para Damiana Kryygi y por este medio el reconocimiento de las violencias implicadas en los procesos de ocupación colonial y de conformación de nuestras naciones. 


\section{CONCLUSIONES}

El encuentro con la historia de Damiana Kryygi, su tratamiento en el marco de la asignatura y posteriormente la participación en la investigación para la elaboración del documental interpelaron nuestra propia práctica como docentes presentándonos nuevos interrogantes en la reflexión sobre el oficio de enseñar la historia de la disciplina. A la vez nos permitió avanzar en la propuesta analítica de la materia según la cual la historia de la antropología forma parte de su "metateoría" y es en sí una práctica de investigación antropológica.

Al inicio de nuestro curso se introduce el "proyecto planetario" de la historia natural, de clasificación y de construcción de inventarios que pretendió abarcar bajo el dominio y la mirada europeos la totalidad del universo en el siglo XVIII (PRATT, 1997). Luego se aborda el proceso que culminó con la consolidación de las relaciones de producción capitalistas en el siglo XIX y su dimensión colonial de conquista (QUIJANO, 2000). En este recorrido histórico, se trabaja con los/las estudiantes para que puedan avizorar cómo el concepto de "civilización" deja de ser un atributo de la humanidad en su conjunto para constituirse en una característica peculiar de ciertas poblaciones nombradas como "razas" y definidas en función de diferencias biológicas heredadas. La estabilización del concepto de raza y el racismo científico del siglo XIX dieron fundamento perdurable a las preocupaciones políticas sobre la capacidad humana hereditaria y el problema de la mezcla y degeneración raciales y la necesidad de regulación de las poblaciones, asegurando la función de sometimiento, encierro, expulsión, tanto como la muerte de salvajes, primitivos y deficientes de todo tipo en nombre de su propia y esencial debilidad estructural.

El análisis sobre el estudio antropológico de Damiana Kryygi y los debates en torno de su historia a partir de la proyección de la película documental no se proponen como "ejemplo" que ilustra esta problemática de la historia de la antropología. El ejercicio de trabajo que proponemos en la materia no es dar una definición de racismo y luego ejemplificar con un caso sino poner en evidencia a través de la reconstrucción de esta historia, la trama compleja que opera en los procesos coloniales de construcción de poder que posibilitó la codificación/naturalización de las diferencias entre grupos humanos y los conceptos, instrumentos, teorías e instituciones y en particular el papel de los museos en la configuración histórica de la disciplina tanto en Alemania como en nuestro país. La historia de Damiana Kryygi encarna y expresa la historia de la violencia y destrucción contra el pueblo aché y al mismo tiempo se constituye en una vía para aprehender la relación que articula el proyecto político colonial, el racismo a partir del siglo XIX y la antropología finisecular.

La inclusión de esta historia en la asignatura no sólo posibilitó el tratamiento de una temática contemplada en el programa sino que favoreció la reflexión acerca de los "lugares" desde donde se construye y enseña la historia. Como diría G. Stocking ( 1982), nos permitió comprender la "plausibilidad" 
de los procesos en vez de buscar una "racionalidad", en tanto atendemos a la historia de los autores pensando más que la de su pensamiento (thinking vs. thought) y a las instituciones y las redes de intercambio funcionando como un proceso "vivo" que se construye y reformula permanentemente.

Asimismo, el encuentro con el itinerario trágico de la vida de la niña y de su pueblo, transformadas en vidas sin valor, eliminables, a partir de los discursos y tecnologías que confluyen en la configuración del concepto de raza y de las ideologías racistas durante el período nos permitió introducir la discusión con y entre los/las estudiantes sobre los racismos contemporáneos. En este marco, entendemos que no existe un racismo sino construcciones sociopolíticas e ideológicas variables según épocas, contextos y coyunturas, que implican la pérdida de ciudadanía y de cualquier valor político positivo de personas y grupos en virtud de su condición étnica, nacional, de género o simplemente fenotípica.

Finalmente, la historia de la niña, y el tratamiento que se le da en la materia y en la película favoreció la construcción de un "puente" entre el pasado y el presente. Por un lado, un puente de las comunidades con su pasado (a partir del proceso de restitución de los restos) y de la Damiana-espécimen con su historia y su vida como Damiana Kryygi. Por otro lado, un puente entre los debates y preocupaciones de la antropología actual con su pasado. A pesar de ser una historia del pasado, también pertenece al presente.

\section{REFERÊNCIAS}

AGAMBEN, G. Profanaciones. Buenos Aires: Adriana Hidalgo Editora, 2005.

ARENAS, P. Ahora Damiana es Kryygi. Restitución de restos a la comunidad aché de Ypetimi, Paraguay. Corpus. Archivos virtuales de la alteridad americana, v. I, n. I, 200 I. Disponível em: http://ppct.caicyt.gov.ar/index.php/corpus/issue/view/30/showToc. Acesso em: 28 jan. 2019

ARENAS, P. Antropología en Argentina. El aporte de los científicos de habla alemana. Buenos Aires: Institución cultural Argentino-Alemana/Museo Etnográfico, | 99 |.

ARENAS, P.; PINEDO, J. Damiana vuelve a los suyos. Diario Página 12, Suplemento Radar. Buenos Aires, 2 I de noviembre de 2005. Disponível em:

http://www.pagina I 2.com.ar/diario/suplementos/radar/9-2639-2005- I I-2 I.html

BILBAO, S. Rememorando a Roberto Lehmann-Nitsche. Buenos Aires: Editorial La Colmena, 2004.

BRISSET MARTíN, D. Acerca de la fotografía etnográfica. Gazeta de Antropología, n. I 5, art, I I, 1999. Disponível em:

http://digibug.ugr.es/bitstream/handle// 048 I/7534/G I 5 I I DemetrioE_Brisset_Martin.pdf?sequence= I o\&isAllowed =y. Acesso em: 28 jan. 2019.

CAIMARI, L. Entre la celda y el hogar. Dilemas estatales del castigo femenino (Buenos Aires, 1890 1940). Nueva Doctrina Penal, n. 2007/B, p. 427-450, 2007.

DIDI-HUBERMAN, G. Cuando las imágenes toman posición. El ojo de la historia, I. Madrid: A. Machado Libros, 2008. 
EDWARDS, E. Raw Histories. Photographs, Anthropology and Museums. Oxford: Berg Publishers, 2001.

FARRO, M. Primer encargado de la Sección Antropológica del Museo de La Plata. Herman Frederik Carel ten Kate. Revista Museo, n. 23, p. 9-16, 2009b. Disponível em:

http://www.fundacionmuseo.org.ar/revistasfundacion/revista-museo-no-23/. Acesso em: 28 jan. 2019.

FARRO. M. La formación del Museo de La Plata. Coleccionistas, comerciantes, estudiosos y naturalistas viajeros a fines del siglo XIX. Rosario, Prohistoria ediciones: 2009a.

GIORDANO, M. De Boggiani a Métraux. Ciencia antropológica y fotografía en el Gran Chaco. Revista Chilena de Antropología Visual, n. 4, p. 365-390, 2004.

KOEL-ABT, K.; WINKELMANN, A. The identification and restitution of human remains from an Aché girl named 'Damiana': An interdisciplinary approach. Annals of Anatomy, v. 195, n. 5, p. 393-400, 2013.

LA HITTE, C. y TEN KATE, H. Notes ethnographiques sur les indiens guayaquis et description de leurs caractères physiques. Anales del Museo de La Plata, Anthropologie, v. II, p. 5-38, 1897.

LAZZARI, A. 2. Reclamos, restituciones y repatriaciones de restos humanos indígenas: cuerpos muertos, identidades, cosmologías, políticas y justicia. Corpus. Archivos virtuales de la alteridad americana, v. I, n. I , 200 I. Disponível em: http://ppct.caicyt.gov.ar/index.php/corpus/issue/view/30/showToc. Acesso em: 28 jan. 2019

KROTZ, E. Utopía, asombro, alteridad: consideraciones metateóricas acerca de la investigación antropológica. Estudios Sociológicos, v. 5, n. I4), p. 283-30I, 1987.

LEHMANN-NITSCHE, R. Relevamiento antropológico de una india guayakí. Revista del Museo de La Plata, n. XV, p: 91-101, 1908.

MARTINEZ, A. Imágenes fotográficas sobre pueblos indígenas: un enfoque antropológico. 20 I0. $205 f$. Tesis Doctoral (Doctorado en Ciencias Naturales). Universidad Nacional de La Plata, 2012. Disponível em: http://sedici.unlp.edu.ar/handle/I0915/505I. Acesso em: 28 jan. 2019

MASSOTA, C. El atlas invisible. Historias de archivo en torno a la muestra 'Almas Robadas - Postales de Indios' (Buenos Aires, 20 I0). Corpus. Archivos virtuales de la alteridad americana, v. I, n. I , 200 I . Disponível em: http://ppct.caicyt.gov.ar/index.php/corpus/issue/view/30/showToc. Acesso em: 28 jan. 2019

MORTON, C.; EDWARDS, E. (eds.) Photography, Anthropology and History. Londres: Ashgate Publishing Limited, 2009.

MÜNZEL, M. Los Aché: El genocidio continúa en Paraguay. In: IWGIA (Grupo Internacional de Trabajo sobre Asuntos Indígenas). In: Los Aché del Paraguay: Discusión de un Genocidio. Copenhague: IWGIA, 2008b. p. 107-133

MÜNZEL, M. Los indígenas Aché: Genocidio en Paraguay. In: IWGIA (Grupo Internacional de Trabajo sobre Asuntos Indígenas). In: Los Aché del Paraguay: Discusión de un Genocidio. Copenhague: IWGIA, 2008a, p. 55- 105.

PEIRANO, M. A teoria vivida e outros ensaios de antropología. Río de Janeiro: Jorge Zahar Editor, 2006 
PERAZZI, P. Cartografías corporales: las pesquisas antropológicas del doctor Roberto Lehmann-Nitsche, Buenos Aires, 1897-1908. Cuadernos de Antropología Social, Buenos Aires, n. 29, p. I23-136, 2009.

PERAZZI, P.; NAME, MJ. La carrera de Ciencias Antropológicas de la UBA ( 1958 - 1 985): continuidades, rupturas y transiciones de sus contenidos curriculares. In: CONGRESO DE HISTORIA DE LA ANTROPOLOGÍA ARGENTINA, 2018, Buenos Aires. Mimeo

POOLE, D. Visión, raza y modernidad. Introducción. In: IEP (Instituto de Estudios Peruanos). Taller Interactivo: Prácticas y Representaciones de la Nación, Estado y Ciudadanía en el Perú, Módulo: "Estudios de caso", Sesión I4, Lectura n. 2, Lima, Perú 2002.

PRATT, ML. Ojos imperiales. Literatura de viajes y transculturización. Bernal: Ediciones de la Universidad Nacional de Quilmes, 1997.

QUIJANO, A. Colonialidad del poder, eurocentrismo y América Latina. In: LANDER. E. (comp.) La colonialidad del saber: eurocentrismo y ciencias sociales. Perspectivas Latinoamericanas. Buenos Aires: CLACSO. Disponível em: http://bibliotecavirtual.clacso.org.ar/clacso/sursur/20100708034410/lander.pdf. Acesso em: 28 jan. 2019.

STOCKING, G. On the limits of 'presentism' and 'historicism' in the historiography of the behavioral sciences. In: Race, culture and evolution. Essays in the History of Anthropology. Chicago/Londres: The University of Chicago Press, 1982 [1968], pp. I- I 2.

STOLER, AL. Race and the Education of Desire. Foucault's history of sexuality and the colonial order of things. Durham y Londres: Duke University Press, 1995.

VÍCTORA, C.; RUAS-NETO, A. Querem matar os 'últimos Charruas': sofrimento social e a 'luta' dos indígenas que vivemnas ciudades. Revista AntHropológicas, v. 22, n. I, p. 37-59, 201 I.

VIRCHOW, H. Kopf eines Guajaki-Mädchens wird vorgelegt. Zeitschrift für Ethnologie, n. XL, p. I I7120, 1908a.

VIRCHOW, H. Carta de Hans Virchow a Robert Lehmann-Nitsche, 18 jan. I 908, Legado Robert Lehmann-Nitsche, Instituto Iberoamericano, Berlín, 1908b. [cartão pessoal]. 